\title{
Percutaneous Absorption in Man: In vitro-in vivo Correlation
}

\author{
P.A. Lehman S.G. Raney T.J. Franz \\ Pre-Clinical Dermatology, Cetero Research, Fargo, N. Dak., USA
}

\section{Key Words}

Percutaneous absorption - In vitro-in vivo correlation •

Bioavailability $\cdot$ Bioequivalence

\begin{abstract}
Aims: To examine the existing literature to determine the degree to which percutaneous absorption data obtained using the excised human skin model match those obtained from living man. Methods: The scientific literature was reviewed to collect data on compounds whose percutaneous absorption through human skin had been measured under both in vitro and in vivo conditions. The in vitro-in vivo (IVIV) correlation was evaluated by computing the in vitro/in vivo ratio using total absorption (percent of applied dose) as the metric for comparison. Results: A total of 92 data sets were collected from 30 published studies. The average IVIV ratio across all values was 1.6 , though for any single data set there could be a nearly 20 -fold difference between the in vitro and in vivo values. In $85 \%$ of the cases, however, the difference was less than 3-fold. The correlation was significantly improved when data were excluded from studies in which the protocols for both studies were not fully harmonized. For harmonized data sets the average IVIV ratio was 0.96 and there was a less than 2-fold difference between the in vitro and in vivo results for any one compound, with IVIV ratios
\end{abstract}

ranging from 0.58 to 1.28 . The dominant factors leading to exclusion of data were the use of skin from different anatomical sites and vehicles of differing composition. Conclusions: Percutaneous absorption data obtained from the excised human skin model closely approximate those obtained from living man when the two study protocols are appropriately matched.

Copyright $\odot 2011$ S. Karger AG, Basel

\section{Introduction}

The use of ex vivo human skin to study the process of percutaneous absorption is widespread and has application within multiple areas of the drug development process as well as in the field of toxicology [1]. Though substantial literature has emerged utilizing this model system, the degree to which it mimics the living state and, therefore, the extent to which the data can be reliably extrapolated must be critically examined. Is it a perfect model and, if not, how reliable are the data? The purpose of this study was to examine the published literature and determine the degree to which data obtained using the excised skin model match those obtained from living man.

\section{KARGER \\ Fax +41613061234 E-Mail karger@karger.ch} www.karger.com
Thomas J. Franz

10716 South East Forest View Lane

Happy Valley, OR 97086 (USA)

Tel. +1 5036983992

E-Mail franzcell@frontier.com 


\section{Methods}

The published scientific literature available in English was reviewed and 30 studies identified in which the percutaneous absorption of the same compound had been measured in human skin under both in vitro and in vivo conditions [2-31]. In some cases the in vitro and in vivo studies on a given compound were conducted by the same laboratory and similar conditions used for both. However, in other cases only an in vitro study was conducted and the results compared with those available in the published literature from an in vivo study. For that reason the protocols for each of the in vitro studies were carefully reviewed to identify the extent to which they matched those utilized in living man. The following potentially critical parameters were examined: (1) skin source/anatomical region; (2) compound concentration (micrograms per milliliter) and dose (micrograms per square centimeter); (3) vehicle dose (microliters per square centimeter or milligrams per square centimeter); (4) vehicle composition; (5) chamber conditions (temperature, humidity, occluded/unoccluded); (6) length of application, protected/unprotected site, wash-off time.

Two analyses were performed: (a) a comparison of the data from all studies irrespective of whether the protocols were fully harmonized, and (b) a comparison of the data from those studies in which full harmonization was documented. The in vitro-in vivo (IVIV) correlation was examined using only the data on total absorption (percent of applied dose) into the receptor solution (in vitro), ignoring residual compound contained within the skin at the time of study conclusion. The IVIV ratio for each compoundvehicle combination was calculated using the mean values for total absorption determined in the two studies being compared. In cases where there were multiple in vitro values and/or multiple in vivo values for the same compound, IVIV ratios were calculated independently for all combinations. Thus, where 9 in vitro values from a multicenter study were available for caffeine [29], and 2 in vivo values [3, 6], a total of 18 IVIV ratios resulted. An overall IVIV ratio was also calculated by averaging across all individual ratios.

\section{Results and Discussion}

\section{All Data: Harmonized and Nonharmonized}

A total of 92 data sets involving 30 organic compounds were collected from 30 published studies (table 1$)^{1}$. Some of the studies contained only in vivo $[2-4,10-12,14,23$, $26,31]$ or in vitro $[5,8,13,17,19-21,24,29]$ data, whereas others contained both sets of data $[6,7,9,15,16,18,22$, $25,27,28,30]$.

In a number of cases the choice of which in vivo study to use as the comparator for the in vitro study was problematic since dissimilar vehicles were often utilized in vitro. For example, a significant body of in vitro data re-

\footnotetext{
1 A more complete table listing essential parameters of individual in vi tro and in vivo studies is available for electronic download on request.
}

sides in the multicenter study of van de Sandt et al. [29], in which the absorption of benzoic acid, caffeine and testosterone were measured from a vehicle consisting of 1:1 ethanol/water. However, none of the studies conducted on living man utilized that same vehicle, making it necessary to choose the most logical match. In this case, in vivo data obtained using an acetone vehicle were chosen as being closer to ethanol/water than data obtained using either petrolatum, ethylene glycol gel or water gel as vehicles. An additional disqualifying factor against the use of in vivo data obtained from the water gel vehicle was its use at an infinite dose $\left(400 \mathrm{mg} / \mathrm{cm}^{2}\right)$, which did not match up favorably with the $25 \mu \mathrm{l} / \mathrm{cm}^{2}$ dose used in vitro.

Thus, where data were available from multiple studies in living man, the comparator data were selected on the basis of which vehicle and dose most closely matched that used in vitro. With three compounds, benzene, caffeine and testosterone, 2 in vivo studies were found equally suitable as comparators for the in vitro data, and both were used.

Examination of the IVIV ratios for the entire data set of 92 demonstrates a clear tendency for the observed values to follow the line of a perfect 1:1 correlation (fig. 1). The average IVIV ratio for the group as a whole was 1.6. However, examination of the data from any individual data set reveals that variability can be great, with ratios ranging from 0.18 to 19.7. Nonetheless, although there is a single example where the in vitro value differs from in vivo by nearly 20 -fold, in $85 \%$ of the data sets the difference is less than 3 -fold.

A review of the methods employed in the studies from which the data of table 1 were taken revealed that there were very few instances in which the in vitro protocol design perfectly matched that utilized in vivo. This lack of harmonization included differences in: (a) the anatomical site from which the skin was obtained, (b) test compound dose, (c) vehicle dose, (d) composition of vehicle, (e) length of exposure/wash time, and (f) the temperature at which the in vitro study was run as well as the use of isothermal rather than anisothermal conditions.

Although the quantitative impact on absorption of some of these differences may have been trivial, two factors that unquestionably influenced the in vitro results were the use of skin from an anatomical site other than that used in vivo, as well the use of a vehicle whose composition did not match that used in vivo. Since regional variation in the permeability of skin is well documented $[32,33]$, as is the ability to alter absorption through vehicle modification [34-38], it is evident that substantial error may exist within the presently available data sets. 
Table 1. Listing of in vitro and in vivo absorption data for 92 data sets

\begin{tabular}{|c|c|c|c|c|c|c|c|}
\hline \multirow[t]{2}{*}{ Compound } & \multirow{2}{*}{$\frac{\text { Vehicle }}{\text { in vitro/in vivo }}$} & \multicolumn{2}{|c|}{$\%$ absorbed } & \multicolumn{2}{|c|}{ IVIV ratio } & \multicolumn{2}{|c|}{ Reference No. } \\
\hline & & in vitro & in vivo & all studies & harmonized & in vitro & in vivo \\
\hline Acetylsalicylic acid & acetone/same & 40.5 & 21.8 & 1.86 & & 5 & 3 \\
\hline Benzene & benzene/same & 0.1 & 0.05 & 2.00 & & 7 & 7 \\
\hline Benzene & benzene/same & 0.1 & 0.07 & 1.43 & & 7 & 31 \\
\hline Benzoic acid & acetone/same & 44.9 & 42.6 & 1.05 & & 5 & 3 \\
\hline Benzoic acid & ethanol/same & 34.48 & 42.6 & 0.81 & & 13 & 3 \\
\hline Benzoic acid & petrolatum/same & 46.5 & 60.6 & 0.77 & 0.77 & 9 & 9 \\
\hline Benzoic acid $^{\mathrm{a}}$ & $1: 1$ aq ethanol/acetone & 63.0 & 42.6 & 1.48 & & 29 & 3 \\
\hline Benzoic acid ${ }^{\mathrm{a}}$ & $1: 1$ aq ethanol/acetone & 51.5 & 42.6 & 1.21 & & 29 & 3 \\
\hline Benzoic acid $^{\mathrm{a}}$ & $1: 1$ aq ethanol/acetone & 83.3 & 42.6 & 1.96 & & 29 & 3 \\
\hline Benzoic acid $^{\mathrm{a}}$ & $1: 1$ aq ethanol/acetone & 86.8 & 42.6 & 2.04 & & 29 & 3 \\
\hline Benzoic acid $^{\mathrm{a}}$ & $1: 1$ aq ethanol/acetone & 42.7 & 42.6 & 1.00 & & 29 & 3 \\
\hline Benzoic acid ${ }^{\mathrm{a}}$ & $1: 1$ aq ethanol/acetone & 68.8 & 42.6 & 1.62 & & 29 & 3 \\
\hline Benzoic acid ${ }^{\mathrm{a}}$ & $1: 1$ aq ethanol/acetone & 90.3 & 42.6 & 2.12 & & 29 & 3 \\
\hline Benzoic acid ${ }^{\mathrm{a}}$ & $1: 1$ aq ethanol/acetone & 77.8 & 42.6 & 1.83 & & 29 & 3 \\
\hline Borax & water/same & 0.41 & 0.21 & 1.95 & & 22 & 22 \\
\hline Boric acid & water/same & 1.75 & 0.23 & 7.61 & & 22 & 22 \\
\hline Disodium octaborate & aqueous??/same & 0.19 & 0.12 & 1.58 & & 22 & 22 \\
\hline Caffeine & acetone/same & 24.1 & 22.1 & 1.09 & 1.09 & 6 & 6 \\
\hline Caffeine & ethylene glycol gel/same & 32.2 & 55.6 & 0.58 & 0.58 & 9 & 9 \\
\hline Caffeine & petrolatum/same & 40.6 & 40.6 & 1.00 & 1.00 & 9 & 9 \\
\hline Caffeine & water gel/same & 5.1 & 4.0 & 1.28 & 1.28 & 9 & 9 \\
\hline Caffeine $\mathrm{a}^{\mathrm{a}}$ & $1: 1$ aq ethanol/acetone & 19.1 & 22.1 & 0.86 & & 29 & 6 \\
\hline Caffeine $\mathrm{a}^{\mathrm{a}}$ & $1: 1$ aq ethanol/acetone & 10.9 & 22.1 & 0.49 & & 29 & 6 \\
\hline Caffeine $\mathrm{a}^{\mathrm{a}}$ & $1: 1$ aq ethanol/acetone & 11.3 & 22.1 & 0.51 & & 29 & 6 \\
\hline Caffeine $\mathrm{a}^{\mathrm{a}}$ & $1: 1$ aq ethanol/acetone & 34.9 & 22.1 & 1.58 & & 29 & 6 \\
\hline Caffeine $^{a}$ & $1: 1$ aq ethanol/acetone & 21.7 & 22.1 & 0.98 & & 29 & 6 \\
\hline Caffeine $\mathrm{a}^{\mathrm{a}}$ & $1: 1$ aq ethanol/acetone & 46.5 & 22.1 & 2.10 & & 29 & 6 \\
\hline Caffeine $^{a}$ & $1: 1$ aq ethanol/acetone & 23.5 & 22.1 & 1.06 & & 29 & 6 \\
\hline Caffeine $^{\mathrm{a}}$ & $1: 1$ aq ethanol/acetone & 32.6 & 22.1 & 1.48 & & 29 & 6 \\
\hline Caffeine $^{a}$ & $1: 1$ aq ethanol/acetone & 20.1 & 22.1 & 0.91 & & 29 & 6 \\
\hline Caffeine $^{\mathrm{a}}$ & $1: 1$ aq ethanol/acetone & 19.1 & 47.6 & 0.40 & & 29 & 3 \\
\hline Caffeine $^{a}$ & $1: 1$ aq ethanol/acetone & 10.9 & 47.6 & 0.23 & & 29 & 3 \\
\hline Caffeine $^{a}$ & $1: 1$ aq ethanol/acetone & 11.3 & 47.6 & 0.24 & & 29 & 3 \\
\hline Caffeine $^{\mathrm{a}}$ & $1: 1$ aq ethanol/acetone & 34.9 & 47.6 & 0.73 & & 29 & 3 \\
\hline Caffeine $^{a}$ & $1: 1$ aq ethanol/acetone & 21.7 & 47.6 & 0.46 & & 29 & 3 \\
\hline Caffeine $^{a}$ & $1: 1$ aq ethanol/acetone & 46.5 & 47.6 & 0.98 & & 29 & 3 \\
\hline Caffeine $^{\mathrm{a}}$ & $1: 1$ aq ethanol/acetone & 23.5 & 47.6 & 0.49 & & 29 & 3 \\
\hline Caffeine $^{a}$ & $1: 1$ aq ethanol/acetone & 32.6 & 47.6 & 0.68 & & 29 & 3 \\
\hline Caffeine $^{\mathrm{a}}$ & $1: 1$ aq ethanol/acetone & 20.1 & 47.6 & 0.42 & & 29 & 3 \\
\hline Chloramphenicol & acetone/same & 2.9 & 2.0 & 1.45 & & 5 & 3 \\
\hline Chloroform ${ }^{\mathrm{b}}$ & water/same & 5.6 & 8.2 & 0.68 & & 18 & 18 \\
\hline Chloroform ${ }^{b}$ & water/same & 7.1 & 8.2 & 0.87 & & 18 & 18 \\
\hline Chlorpyrifos & Dursban 4:water/same & 19.7 & 1.0 & 19.70 & & 24 & 23 \\
\hline Coumarin & ethanol/70\% aq ethanol & 50.4 & 59.7 & 0.84 & & 20 & 26 \\
\hline Diazinon & acetone/same & 14.1 & 3.2 & 4.41 & & 16 & 16 \\
\hline DNCB & acetone/same & 27.5 & 53.1 & 0.52 & & 5 & 3 \\
\hline DNCB & acetone/same & 32.5 & 53.1 & 0.61 & & 8 & 3 \\
\hline Fluazifop-butyl ${ }^{\mathrm{c}}$ & aq suspension/same & 2.2 & 6.4 & 0.34 & & 17 & 14 \\
\hline Fluazifop-butyl ${ }^{\mathrm{c}}$ & aq suspension/same & 2.8 & 2.7 & 1.04 & & 17 & 14 \\
\hline Fluazifop-butyl ${ }^{\mathrm{c}}$ & aq suspension/same & 2.4 & 1.3 & 1.85 & & 17 & 14 \\
\hline Hippuric acid & acetone/same & 1.25 & 1.0 & 1.25 & 1.25 & 6 & 6 \\
\hline Isofenphos & acetone/same & 2.5 & 3.6 & 0.69 & & 15 & 15 \\
\hline Lindane & acetone/same & 0.69 & $3.9^{\mathrm{d}}$ & 0.18 & & 21 & 4 \\
\hline
\end{tabular}


Table 1 (continued)

\begin{tabular}{|c|c|c|c|c|c|c|c|}
\hline \multirow[t]{2}{*}{ Compound } & \multirow{2}{*}{$\frac{\text { Vehicle }}{\text { in vitro/in vivo }}$} & \multicolumn{2}{|c|}{$\%$ absorbed } & \multicolumn{2}{|c|}{ IVIV ratio } & \multicolumn{2}{|c|}{ Reference No. } \\
\hline & & in vitro & in vivo & all studies & harmonized & in vitro & in vivo \\
\hline Lindane & emulsion/acetone & 3.2 & $8.3^{\mathrm{d}}$ & 0.39 & & 21 & 4 \\
\hline Lindane & $93 \%$ white spirit/acetone & 15.3 & $8.3^{\mathrm{d}}$ & 1.84 & & 21 & 4 \\
\hline Lindane & $\sim 100 \%$ white spirit/acetone & 25.7 & $8.3^{\mathrm{d}}$ & 3.10 & & 21 & 4 \\
\hline Lindane & lotion (Kwell)/acetone & 71.7 & $8.3^{\mathrm{d}}$ & 8.64 & & 19 & 4 \\
\hline Mexoryl SX & $\mathrm{o} / \mathrm{w}$ emulsion/same & 0.07 & 0.01 & 7.00 & & 28 & 28 \\
\hline Nicotinamide & acetone/same & 28.8 & 11.1 & 2.59 & & 5 & 3 \\
\hline Nicotinic acid & acetone/same & 2.3 & 2.1 & 1.10 & 1.10 & 6 & $6^{\mathrm{e}}$ \\
\hline Nicotinic acid & ethanol/acetone & 0.6 & 2.1 & 0.29 & & 13 & $6^{\mathrm{e}}$ \\
\hline Nitrobenzene & acetone/same & 7.8 & 1.5 & 5.20 & & 8 & 3 \\
\hline$o$-Phenylphenol & $60 \%$ aq ethanol/same & 31.9 & 26.7 & 1.19 & & 27 & 27 \\
\hline$p$-Phenylenediamine & L'Oreal formulation/same & 1.14 & 0.54 & 2.11 & & 30 & 30 \\
\hline Phenol & acetone/same & 10.9 & 4.4 & 2.48 & & 5 & 3 \\
\hline Phenol & ethanol/95\% ethanol & 19.6 & 24.0 & 0.82 & & 13 & 12 \\
\hline Propoxur & $60 \%$ aq ethanol/same & 9.7 & 3.7 & 2.62 & & 25 & 25 \\
\hline Salicylic acid & acetone/same & 12 & 22.8 & 0.53 & & 5 & 3 \\
\hline Testosterone & ethylene glycol gel/same & 23.7 & 36.3 & 0.65 & 0.65 & 9 & 9 \\
\hline Testosterone & petrolatum/same & 39.4 & 49.5 & 0.80 & 0.80 & 9 & 9 \\
\hline Testosterone & water gel/same & 41.4 & 49.2 & 0.84 & 0.84 & 9 & 9 \\
\hline Testosterone $\mathrm{e}^{\mathrm{a}}$ & $1: 1$ aq ethanol/acetone & 8.4 & 13.2 & 0.64 & & 29 & 2 \\
\hline Testosterone $^{\mathrm{a}}$ & $1: 1$ aq ethanol/acetone & 6.3 & 13.2 & 0.48 & & 29 & 2 \\
\hline Testosterone $\mathrm{e}^{\mathrm{a}}$ & $1: 1$ aq ethanol/acetone & 3.9 & 13.2 & 0.30 & & 29 & 2 \\
\hline Testosterone $^{\mathrm{a}}$ & $1: 1$ aq ethanol/acetone & 13.5 & 13.2 & 1.02 & & 29 & 2 \\
\hline Testosterone $\mathrm{e}^{\mathrm{a}}$ & $1: 1$ aq ethanol/acetone & 8.5 & 13.2 & 0.64 & & 29 & 2 \\
\hline Testosterone $^{\mathrm{a}}$ & $1: 1$ aq ethanol/acetone & 38.9 & 13.2 & 2.95 & & 29 & 2 \\
\hline Testosterone $\mathrm{e}^{\mathrm{a}}$ & $1: 1$ aq ethanol/acetone & 5.2 & 13.2 & 0.39 & & 29 & 2 \\
\hline Testosterone $^{\mathrm{a}}$ & $1: 1$ aq ethanol/acetone & 5.3 & 13.2 & 0.40 & & 29 & 2 \\
\hline Testosterone $\mathrm{e}^{\mathrm{a}}$ & $1: 1$ aq ethanol/acetone & 15.8 & 13.2 & 1.20 & & 29 & 2 \\
\hline Testosterone $\mathrm{e}^{\mathrm{a}}$ & $1: 1$ aq ethanol/acetone & 8.4 & 18 & 0.47 & & 29 & 10 \\
\hline Testosterone $\mathrm{e}^{\mathrm{a}}$ & $1: 1$ aq ethanol/acetone & 6.3 & 18 & 0.35 & & 29 & 10 \\
\hline Testosterone $^{\mathrm{a}}$ & $1: 1$ aq ethanol/acetone & 3.9 & 18 & 0.22 & & 29 & 10 \\
\hline Testosterone $\mathrm{e}^{\mathrm{a}}$ & $1: 1$ aq ethanol/acetone & 13.5 & 18 & 0.75 & & 29 & 10 \\
\hline Testosterone $\mathrm{e}^{\mathrm{a}}$ & $1: 1$ aq ethanol/acetone & 8.5 & 18 & 0.47 & & 29 & 10 \\
\hline Testosterone $\mathrm{e}^{\mathrm{a}}$ & $1: 1$ aq ethanol/acetone & 38.9 & 18 & 2.16 & & 29 & 10 \\
\hline Testosterone $^{\mathrm{a}}$ & $1: 1$ aq ethanol/acetone & 5.2 & 18 & 0.29 & & 29 & 10 \\
\hline Testosterone $\mathrm{e}^{\mathrm{a}}$ & $1: 1$ aq ethanol/acetone & 5.3 & 18 & 0.29 & & 29 & 10 \\
\hline Testosterone $\mathrm{e}^{\mathrm{a}}$ & $1: 1$ aq ethanol/acetone & 15.8 & 18 & 0.88 & & 29 & 10 \\
\hline Thiourea & acetone/same & 4.6 & 3.7 & 1.24 & 1.24 & 6 & 6 \\
\hline Triclopyr BEE & Neat/Garlon 4 & 0.7 & 1.7 & 0.41 & & 13 & 11 \\
\hline Urea & acetone/same & 11.1 & 6.0 & 1.85 & & 5 & 3 \\
\hline
\end{tabular}

aq = Aqueous solution; $\mathrm{o} / \mathrm{w}=$ oil in water. ${ }^{\mathrm{a}}$ In vitro data from individual laboratories in a multicenter study. ${ }^{\mathrm{b}}$ Chloroform applied in vitro at 2 different doses. ${ }^{\mathrm{c}}$ Fluazifop-butyl applied at 3 different doses in both studies. ${ }^{\mathrm{d}}$ Value selected based on in vivo dose which best matched that used in vitro. ${ }^{e}$ Value reported in reference 3 not used due to calculation error.

A major problem is that most studies in living man have utilized the ventral forearm as the site of application, largely for convenience sake, and this is a site not easily obtained for use in the in vitro model. The comparisons are almost always between breast or abdominal skin and the ventral forearm. Use of skin from a site other than that used in vivo is found in 76 of the 92 data sets listed in table 1. Likewise, acetone is the most common vehicle used in in vivo studies, yet some of the potentially useful in vitro data were obtained using ethanol or various aqueous dilutions of ethanol. When these two factors are combined - differences in vehicle composition and ana- 


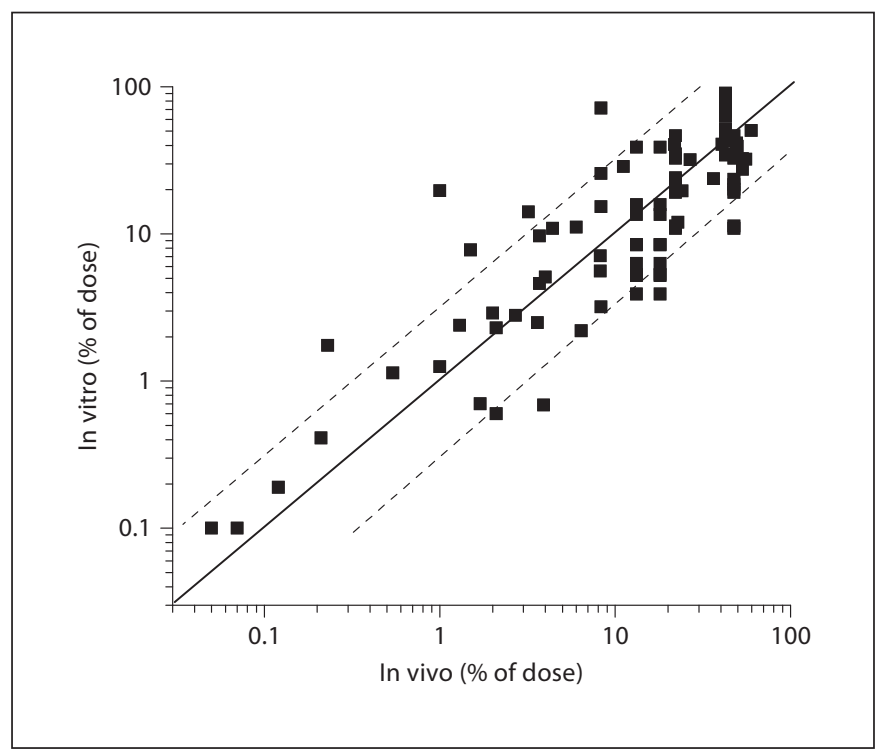

Fig. 1. IVIV ratios of total absorption for all 92 data sets plotted on log-log scale. The IVIV ratios ranged from 0.18 to 19.7 , with an overall mean of 1.6. Solid line: ideal 1:1 correlation. Dashed lines: \pm 3 -fold difference from ideal.

tomical skin site - the data from 80 of the 92 data sets can be assumed to be unsuitable for the purposes of IVIV comparison. A single study was also identified in which skin site and vehicle composition were the same, but the compound dose applied in vitro was 8 -fold lower than that used in vivo [16].

\section{Harmonized Data}

Eleven data sets from 2 studies (table 1) were identified in which the percutaneous absorption of several compound/vehicle combinations was measured in the in vitro model under conditions that matched those utilized in vivo in all critical aspects $[6,9]$. All experiments were conducted using abdominal skin as the site of application, and the six test compounds studied were incorporated into vehicles of identical composition and applied at the same compound and vehicle doses. The single exception, a difference in testosterone dose from that of the ethylene glycol gel, was considered too small to be of consequence $\left(2 \mu \mathrm{g} / \mathrm{cm}^{2}\right.$ in vitro vs. $3 \mu \mathrm{g} / \mathrm{cm}^{2}$ in vivo). Of equal importance, the in vitro studies were conducted under conditions designed to mimic those existing in vivo, i.e. environmental control to match the temperature and water gradients typically found in living man. Specifically, the temperature of the receptor chamber was controlled at a level to maintain the outer skin surface

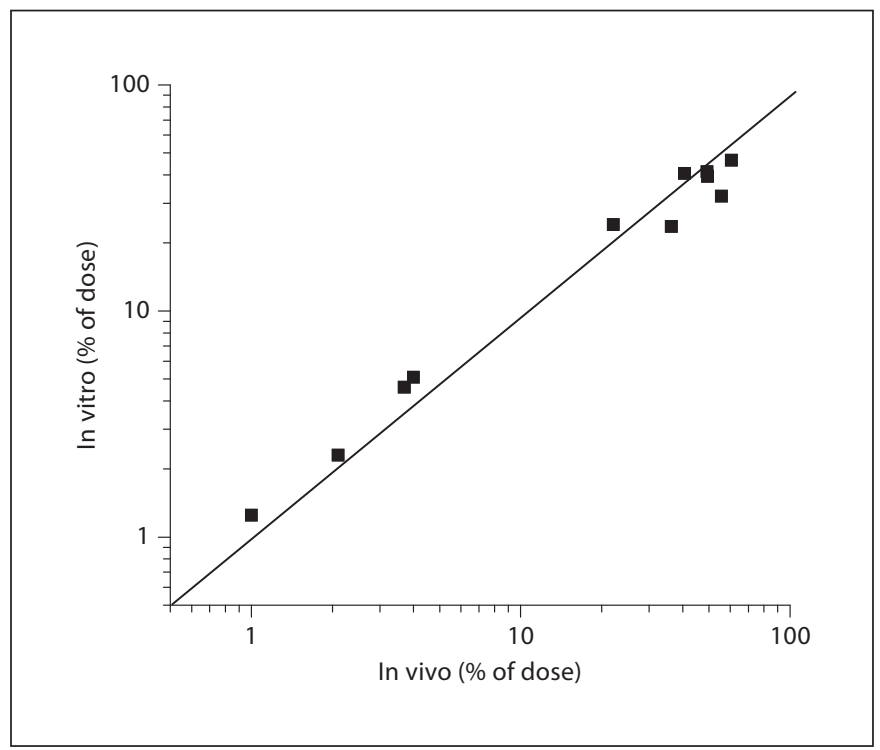

Fig. 2. IVIV ratios of total absorption for 11 fully harmonized data sets plotted on log-log scale. The IVIV ratios ranged from 0.58 to 1.28 , with an overall mean of 0.96 . Line: ideal 1:1 correlation.

temperature at $32^{\circ} \mathrm{C}$, and the donor chamber was left unoccluded so that the stratum corneum was exposed to standard ambient conditions.

Two potentially confounding factors specific to studies in human subjects were also controlled. The processes of rub-off, wash-off and desquamation can all result in a variable reduction in surface dose that cannot be matched in vitro. For that reason the dosed sites in vivo were protected with nonocclusive guards to prevent rub-off, and the subjects were prohibited from bathing during the study or participating in activities that would produce sweating. Likewise, to minimize the influence of desquamation, the applied doses were removed at a specific time in both the in vitro and in vivo studies ( 24 or $36 \mathrm{~h}$ ), and the application sites washed. Since approximately 1 stratum corneum cell layer is lost per day, the effect of desquamation should be minimal at $24 \mathrm{~h}$ [5], particularly given that the skin is protected from rub-off and wash-off during this time period. The experiments utilizing the 36-hour time period were further protected by the nature of the vehicle and the size of the dose applied, petrolatum and ethylene glycol gel at either 25 or $50 \mathrm{mg} / \mathrm{cm}^{2}$. These semi-infinite doses were sufficiently large and stable to remain in place during the entire dosing period and to physically prevent the loss of any cellular material from below. 
Examination of the IVIV ratios from these 11 data sets reveals an unmistakable improvement in correlation from that seen with nonharmonized data (fig. 2). The average ratio for the group as a whole now approached 1 (0.96) and, more importantly, the ratio for any individual data set differed from 1 by less than a factor of 2 (range: $0.58-1.28$ ). This analysis makes it exceedingly clear that the data obtained from the excised human skin model closely replicated those obtained from living man when the two study protocols were appropriately coordinated.

Although the in vitro protocols from the 2 harmonized studies closely matched those used in vivo, they differed from each other in one important aspect. One study in which only highly water-soluble compounds (caffeine, hippuric acid, nicotinic acid, thiourea) were evaluated was conducted using full-thickness skin [6]. In the second study dermatomed skin (approx. $350 \mu \mathrm{m}$ in thickness) was used since testosterone, a compound with limited water solubility, was included along with benzoic acid and caffeine [9]. Although the preference of most researchers in the field is to use split-thickness skin or even isolated epidermis, as it avoids the potential creation of a dermal 'barrier' to the penetration of water-insoluble compounds, the data show that fullthickness skin is a valid alternative for water-soluble compounds.

When evaluating the absorption of poorly water-soluble compounds such as testosterone, not only is it recommended to use split-thickness or dermatomed skin, but care must also be taken to select a receptor solution with adequate solubility for the test substance. Commonly, additives such as bovine serum albumin or polyethylene glycol 20 oleyl ether are used. However, the testosterone data presented in table 1 show excellent IVIV correlations in spite of the fact that normal saline was used as the receptor. The reason for this is clear. The testosterone dose was only in the range of $1-2 \mu \mathrm{g} / \mathrm{cm}^{2}$ and the highest average testosterone flux observed was $<0.024 \mu \mathrm{g} / \mathrm{cm}^{2} / \mathrm{h}$. Since Bronaugh and Stewart [39] have reported the testosterone water solubility to be $11 \mu \mathrm{g} / \mathrm{ml}$, and with a flow rate in the receptor chambers of $5 \mathrm{ml} / \mathrm{h}$ (flow-through chambers), the maximal concentration achieved was always 1,000 -fold lower than saturation.

As pointed out in several guidance documents, the consensus of international experts in the field of percutaneous absorption is that a receptor solution in which the maximum solubility of the test compound is 10 times higher than that needed under experimental conditions is sufficient to maintain sink conditions and minimize back-diffusion [40, 41]. In situations where the rate of absorption is quite low, on the order of nanograms per square centimeter per hour, even isotonic saline can serve as an adequate receptor for some compounds traditionally considered to be water insoluble.

\section{Conclusions}

Past studies of IVIV correlation have generally shown good agreement between data obtained by the in vitro model and those obtained from living man; however, the precision of that agreement has been unnecessarily distorted by comparing data obtained from different anatomical skin sites as well as data obtained using different vehicles. Analysis of the results of 11 data sets obtained from 2 studies in which the in vitro protocol appropriately duplicated the in vivo protocol with respect to all critical parameters revealed a nearly perfect $1: 1$ relationship between the two when averaging across all data. Furthermore, for any single data set, the difference between in vitro and in vivo absorption was less than a factor of 2 . Harmonization of protocols is essential to insure good IVIV correlation.

\section{References}

1 Franz TJ, Lehman PA, Raney SG: The cadaver skin absorption model and the drug development process. Pharmacopeial Forum 2008;34:1349-1356.

$\checkmark 2$ Feldmann RJ, Maibach HI: Percutaneous penetration of steroids in man. J Invest Dermatol 1969;52:89-94.

3 Feldmann RJ, Maibach HI: Absorption of some organic compounds through the skin in man. J Invest Dermatol 1970;54:399-404.
4 Maibach HI, Feldmann RJ: Systemic absorption of pesticides through the skin of man; in Occupational Exposure to Pesticides. Report to the Federal Working Group on Pest Management from the Task Group on Occupational Exposure to Pesticides, Appendix B. Washington DC US Government Printing Office, 1975, pp 120-127.

\footnotetext{
5 Franz TJ: Percutaneous absorption: on the relevance of in vitro data. J Invest Dermatol 1975;64:190-195.

6 Franz TJ: The finite dose technique as a valid in vitro model for the study of percutaneous absorption in man; in Simon GA, Paster A, Klingberg MA, Kaye M (eds): Skin. Drug Application and Evaluation of Environmental Hazards. Curr Probl Dermatol. Basel, Karger, 1978, vol 7, pp 58-68.
} 
7 Franz TJ: Percutaneous absorption of benzene; in MacFarland HM (ed): Applied Toxicology of Petroleum Hydrocarbons. Adv Modern Environ Toxicol. Princeton, Princeton Scientific, 1984, vol 6, pp 61-70.

$\checkmark 8$ Bronaugh RL, Maibach HI: Percutaneous absorption of nitroaromatic compounds: in vivo and in vitro studies in the human and monkey. J Invest Dermatol 1985;84:180-183.

$\checkmark 9$ Bronaugh RL, Franz TJ: Vehicle effect on percutaneous absorption: in vivo and in vitro comparisons. Br J Dermatol 1986;115:111.

-10 Bucks DAW, McMaster JR, Maibach HI, Guy RH: Bioavailability of topically administered steroids: a 'mass balance' technique. J Invest Dermatol 1988;91:29-33.

-11 Carmichael NG, Nolan RJ, Perkins JM, Dabies R, Warrington SJ: Oral and dermal pharmacokinetics of triclopyr in human volunteers. Hum Toxicol 1989;8:431-437.

12 Bucks DAW, Guy RH, Maibach HI: Percutaneous penetration and mass balance accountability: technique and implications for dermatology. J Toxicol Cutaneous Ocul Toxicol 1990;8:439-451.

13 Hotchkiss SAM, Hewitt P, Caldwell J: Percutaneous absorption of nicotinic acid, phenol, benzoic acid and triclopyr butoxyethyl ester through rat and human skin in vitro: further validation of an in vitro model by comparison with in vivo data. Food Chem Toxicol 1992;30:891-899.

-14 Ramsey JD, Woollen BH, Auton TR, Batten TR, Leeser PL: Pharmacokinetics of fluazifop-butyl in human volunteers. 2. Dermal dosing. Hum Exp Toxicol 1992;11:247-254.

-15 Wester RC, Maibach HI, Melendres J, Sedik L, Knaak J, Wang R: In vivo and in vitro percutaneous absorption and skin evaporation of isofenphos in man. Fundam Appl Toxicol 1992;19:521-526.

-16 Wester RC, Sedik L, Melendres J, Logan F, Maibach HI, Russell I: Percutaneous absorption of diazinon in humans. Food Chem Toxicol 1993;31:569-572.

-17 Ramsey JD, Woollen BH, Auton TR, Scott $\mathrm{RC}$ : The predictive accuracy of in vitro measurements for the dermal absorption of a lipophilic penetrant (fluazifop-butyl) through rat and human skin. Fundam Appl Toxicol 1994;23:230-236.

-18 Dick D, Ng KM, Sauder DN, Chu I: In vitro and in vivo percutaneous absorption of ${ }^{14} \mathrm{C}$ chloroform in humans. Hum Exp Toxicol $1995 ; 14: 260-265$.
19 Franz TJ, Lehman PA, Franz SF, Guin JD: Comparative percutaneous absorption of lindane and permethrin. Arch Dermatol 1996;132:901-905.

-20 Beckley-Kartey SAJ, Hotchkiss SAM, Capel $\mathrm{M}$ : Comparative in vitro skin absorption and metabolism of coumarin (1,2-benzopyrone) in human, rat and mouse. Toxicol Appl Pharmacol 1997;145:34-42.

21 Dick IP, Blain PG, Williams FM: The percutaneous absorption and skin distribution of lindane in man. 2. In vitro studies. Hum Exp Toxicol 1997; 16:652-657.

22 Wester RC, Hui X, Hartway T, Maibach HI, Bell K, Schell MJ, Northington DJ, Strong P, Culver BD: In vivo percutaneous absorption of boric acid, borax, and disodium octaborate tetrahydrate in humans compared to in vitro absorption in human skin from infinite and finite doses. Toxicol Sci 1998;45:42-51.

$\checkmark 23$ Griffin P, Mason H, Heywood K, Cocker J: Oral and dermal absorption of chlorpyrifos: a human volunteer study. Occup Environ Med 1999;56:1-10.

24 Griffin P, Payne M, Mason H, Freedlander E, Curran AD, Cocker J: The in vitro percutaneous penetration of chlorpyrifos. Hum Exp Toxicol 2000;19:104-107.

25 van de Sandt JJ, Meuling WJ, Elliott GR, Cnubben HH, Hakkert BC: Comparative in vitro-in vivo percutaneous absorption of the pesticide propoxur. Toxicol Sci 2000;58:1522

26 Ford RA, Hawkins DR, Mayo BC, Api AM: The in vivo dermal absorption and metabolism of $\left[4-{ }^{14} \mathrm{C}\right]$ coumarin by rats and by human volunteers under simulated conditions of use in fragrances. Food Chem Toxicol 2001;39:153-162.

-27 Cnubben NHP, Elliott GR, Hakkert BC, Meuling WJA, van de Sandt JJM: Comparative in vitro-in vivo percutaneous penetration of the fungicide ortho-phenylphenol. Regul Toxicol Pharmacol 2002;35:198-208.

-28 Benech-Kieffer F, Meuling WJA, Leclerc C, Roza L, Leclaire J, Nohynek G: Percutaneous absorption of Mexoryl SX ${ }^{\circledR}$ in human volunteers: comparison with in vitro data. Skin Pharmacol Appl Skin Physiol 2003;16:343355.

29 van de Sandt JJM, van Burgsteden JA, Cage S, Carmichael PL, Dick I, Kenyon S, Korinth G, Larese F, Limasset JC, Maas WJM, Montomoli L, Nielsen JB, Payan JP, Robinson E, Sartorelli P, Schaller KH, Wilkinson SC, Williams FM: In vitro predictions of skin absorption of caffeine, testosterone, and benzoic acid: a multi-centre comparison study Regul Toxicol Pharmacol 2004;39:271-281.
30 Hueber-Becker F, Nohynek GJ, Meuling WJA, Benech-Kieffer F, Toutain H: Human systemic exposure to a $\left[{ }^{14} \mathrm{C}\right]$-para-phenylenediamine-containing oxidative hair dye and correlation with in vitro percutaneous absorption in human or pig skin. Food Chem Toxicol 2004;42:1227-1236.

-31 Modjtahedi BS, Maibach HI: In vivo percutaneous absorption of benzene in man: forearm and palm. Food Chem Toxicol 2008;46: 1171-1174.

32 Feldmann RJ, Maibach HI: Regional variation in percutaneous penetration of ${ }^{14} \mathrm{C}$-cortisol in man. J Invest Dermatol 1967;48:181183.

33 Wester RC, Maibach HI: Regional variation in percutaneous absorption: principles and applications to human risk assessment; in Bronaugh RL, Maibach HI (eds): Percutaneous Absorption. Drugs-Cosmetics-Mechanisms-Methodology. New York, Taylor \& Francis, 2005, pp 85-93.

$>34$ Barrett CD, Hadgraft JW, Sarkany I: The influence of vehicles on skin penetration. J Pharm Pharmacol 1964;16:104T-107T.

-35 Sarkany I, Hadgraft JW, Caron GA, Barrett CW: The role of vehicles in the percutaneous absorption of corticosteroids. Br J Dermatol 1965;77:569-575.

36 Coldman WD, Poulsen BJ, Higuchi T: Enhancement of percutaneous absorption by the use of volatile:nonvolatile systems as vehicles. J Pharm Sci 1969;58:1098-1102.

37 Ostrenga J, Steinmetz C, Poulsen BJ: Significance of vehicle composition. 1. Relationship between topical vehicle composition, skin penetrability, and clinical efficacy. J Pharm Sci 1971;60:1175-1179.

-38 Franz TJ: On the bioavailability of topical formulations of clindamycin hydrochloride. J Am Acad Dermatol 1983;9:66-73.

39 Bronaugh RL, Stewart RF: Methods for in vitro percutaneous absorption studies. 3. Hydrophobic compounds. J Pharm Sci 1984;73: 1255-1258.

40 Organization for Economic Co-operation and Development (OECD): Guidance document for the conduct of skin absorption studies, Number 28. Paris, OECD, 2004.

-41 Howes D, Guy R, Hadgraft J, Heylings J, Hoeck U, Kemper F, Maibach H, Marty J, Merk H, Parra J, Rekkas D, Rondelli I, Schaefer H, Tauber U, Verbiese N: Methods for assessing percutaneous absorption. European Centre for the Validation of Alternative Methods (ECVAM) Workshop Report 13. Altern Lab Anim 1996;24:81-106. 